\title{
Contribuições da Lei de Responsabilidade Fiscal para o avanço da Accountability no Brasil
}

\author{
Ana Rita Silva Sacramento ${ }^{1}$
}

RESUMO: O objetivo deste paper é apresentar uma revisão da literatura que aborda a questão da accountability no Brasil recente. Para tanto, constrói-se um referencial teórico apresentando-se inicialmente o conceito de accountability, termo que como se sabe ainda não tem tradução direta para o português. Em seguida, revisa-se as suas principais características e a visão predominante dos estudiosos que consideram os mecanismos brasileiros de accountability deficientes. Não obstante tal deficiência, devido à concretização de algumas iniciativas, pouco a pouco a accountability parece-nos estar se fortalecendo no Brasil. Dentre essas iniciativas priorizamos a análise da Lei de Responsabilidade Fiscal sob tal enfoque e concluímos que a referida Lei constitui-se num avanço concreto e atual desse processo. Importante salientar o caráter preliminar desse estudo, visto que a análise está concentrada no referencial teórico e que a coleta de dados empíricos encontra-se em fase de andamento. Ademais, dado a crescente literatura sobre o tema, reconhecemos que este paper não esgota o assunto, uma vez que outras abordagens relevantes possivelmente não estão tratadas aqui, inclusive por razões de espaço e de prioridades analíticas.

PALAVRAS CHAVE: responsabilidade fiscal, accountability

ABSTRACT: The purpose of this paper is to present a review of the literature that approaches the issue of accountability in recent Brazil. For this reason, a framework was built to show firstly the concept of accountability, an expression for which, it is known, do not have equivalent meaning into portuguese language. Secondly, a revision was done as to the predominant vision of experts who consider the Brazilian mechanisms of accountability as deficient. Notwithstanding such a deficiency, due to the realization of some iniciatives, accountability seems little by little to get stronger in Brazil In these iniciatives we give priority to the Fiscal Responsibility Law under such a focus and conclude that the afore mentioned Law represents a concrete and current advance of this process. It is important to emphasize the preliminary nature of this study as the analysis is focused on the theoretical basis and the assessment of empirical data is still under way. Moreover, because of the increasing literature on this subject, we realize that this paper does not exhaust the subject since other relevant approaches are possibly not mentioned here including for reasons of space and analytical priorities.

KEY WORDS: Fiscal Responsibility Law, Accountability

\footnotetext{
${ }^{1}$ Mestre em Administração UFBA pesquisadora do NPGA / EAUFBA. Rua Taperoá, 182- Condomínio Villa Verde, n 27 - CASEB Feira de Santana - Bahia - CEP: 44.040.140 e-mail : anasacramentos@bol.com.br
} 


\section{Accountability: A construção de um conceito}

De origem anglo-saxão e ainda sem tradução direta em outros idiomas como o português (CAMPOS, 1990:30) e o francês (TROSA, 2001:265), palavra accountability geralmente tem sido tratada na literatura por responsabilização e, nas atuais discussões sobre a eficiência da ação governamental e da democracia, tem ocupado posição de destaque. Segundo Schedler (1999:13-27) muito embora em todo o mundo instituições financeiras, lideres de partidos, ativistas de bases, jornalistas e cientistas políticos, tenham descoberto as bênçãos e aderido à causa da accountability pública, devido a sua relativa novidade esta ainda representa um conceito sub explorado, cujo significado permanece evasivo, com fronteiras indefinidas e estrutura interna confusa. Neste cenário, a busca de instrumentos que contribuam para a sua introdução ou ampliação do seu grau na administração pública tem sido também uma tônica do debate político e objeto de inovação institucional nos Estados democráticos contemporâneos que, adeptos a gestão pública orientada pela lógica do cidadão-cliente, colocaram o tema da accountability definitivamente na agenda de reformas (LOUREIRO \& ABRÚCIO, 2002:65).

Num dos trabalhos seminais que buscam a sua compreensão no idioma português, Campos (1990) inspira-se em Frederich Mosher para concluir que a accountability é sinônimo de responsabilidade objetiva, isto é, trata-se da responsabilidade de uma pessoa ou organização perante outra, fora de si mesma. Ainda segundo esta autora, o grau de accountability avança na medida em que os valores democráticos, tais como igualdade, dignidade humana, participação e representatividade, também avançam. Pensamento semelhante encontramos em Anastasia \& Melo (2002:25) que também admitem a accountability como um atributo da democracia que implica o controle dos governantes pelos governados e em Levy (1999:390) que a define como a "obrigação de prestar contas e assumir responsabilidades perante aos cidadãos imposta àqueles que detêm o poder de Estado objetivando criar transparências e, conseqüentemente, maiores condições de confiança entre governantes e governados". Ainda segundo esta autora, a accountability "se refere não somente à premissa da prestação de contas, mas também a definição dos objetos sobre os quais se prestarão contas". Para Stark \& Bruszt (1998) a expressão "prestar contas de" tem ao mesmo tempo, o sentido de contabilidade e narrativa. Essas duas dimensões partem de julgamentos, e cada uma pressupõe a outra. 
Para Przeworski (1998:61) os governos são responsáveis se os cidadãos têm como saber se aqueles estão ou não estão atuando na defesa dos interesses públicos e podem lhes aplicar as sanções apropriadas, de tal modo que os políticos que atuarem a favor dos interesses dos cidadãos sejam reeleitos e os que não o tenham feito percam as eleições.

Neste ponto, concorda-se com Schedler (1999), para quem a verdadeira razão de ser da accountability reside na pressuposição da existência do poder e, neste sentido, o seu principal objetivo não é eliminá-lo, mas controlá-lo. Ainda segundo este autor, o "estreito acasalamento" da accountability e a viabilidade de sanções, reflete o senso comum neoinstitucionalista. Nesta literatura, as regras para serem efetivas devem estar acompanhadas de mecanismos de monitoramento, evitando que violações passem desapercebidas e trapaças permaneçam impunes (SCHEDLER 1999:16).

Trosa (2001: 264) alerta para a necessidade de uma visão moderna de responsabilidade, visto que esta não pode ter como base a ameaça e a sanção, mas um sentimento interiorizado que "cada um faz parte da solução e não apenas do problema". Esta acepção está alinhada ao que Campos (1990) denomina de responsabilidade subjetiva, isto é, à cobrança que a pessoa exerce sobre si mesma quanto à necessidade de prestar contas a alguém.

Observa-se até aqui a existência de um consenso na literatura pesquisada de que a accountability é um subconjunto da democracia, pois como afirmam Anastasia \& Melo (2002), apesar da controvérsia suscitada pelo último conceito esta diz respeito à, no mínimo, "processos através dos quais cidadãos comuns exercem um grau relativamente alto de controle sobre líderes" (DAHL, citado por ANASTASIA \& MELO, 2002:25) ou ainda Schedler (1999), que considera a accountability antitética ao poder monólogo, visto que uma vez que estabelece um relacionamento entre atores responsáveis e responsivos opõe-se não apenas ao poder mudo, mas também ao controle silencioso e unilateral do poder e mais ainda O`Donnell (citado por FEDOZZI, 1997:93) ao chamar a atenção para dois aspectos principais da accountability: a) a obrigação do governante e do funcionário de sujeitar seus atos à lei; b) a obrigação do governante de prestar contas dos seus atos, com suficiente transparência para que a cidadania possa avaliar sua gestão e, mediante procedimentos democráticos, ratificá-las ou rechaçá-la. 
Do exposto, conclui-se que a accountability é uma das características do sistema político que nos regimes democráticos se impõe ao administrador público. Portanto, a accountability não só diz respeito à imposição, pelo sistema, em caráter continuado, de visibilidade e transparência nos atos do governo como também à responsabilização dos governantes, inclusive com a possibilidade de sanções, pelos governados.

Nesse paper, adotamos o conceito de accountability de Loureiro \& Abrúcio (2002:59) por considerar que este contempla o que foi acima exposto. Para estes autores:

"Accountability é um processo institucionalizado de controle político estendido no tempo (eleição e mandato) e no qual devem participar, de um modo ou de outro, os cidadãos organizados politicamente. Para isso, são necessárias regras e arenas nas quais a accountability é exercida, além de práticas de negociação ampliadas entre os atores, para tornar as decisões mais públicas e legitimas".

\section{Aspectos gerais da accountability}

A concepção de O’Donnell (1998) estabelece que são duas as dimensões da accountability, a vertical e a horizontal. As ações realizadas individualmente e/ou coletivamente, com referência aos que, eleitos ou não, exercem posições em instituições do Estado fazem parte da accountability vertical, ao passo que, as agências estatais possuidoras de direito, poder legal, disposição e capacidade para realizar ações, que vão desde a supervisão de rotina e sanções legais ou até o impeachment contra ações ou omissões de outros agentes ou agências do estado que possam ser qualificadas como delituosas, fazem parte da accountability horizontal. Destacam-se como principais integrantes da primeira dimensão as eleições eleitorais, as reivindicações sociais livremente proferidas e a atuação da mídia divulgando tais reivindicações - ao menos as mais visíveis - e os atos supostamente ilícitos de autoridades públicas. E, como mecanismos da segunda dimensão, as instituições clássicas das poliarquias a saber: o Executivo, o Legislativo, o Judiciário, as agências de supervisão e as instâncias responsáveis pela fiscalização das prestações de contas. Concluise, portanto, que na concepção desse autor, enquanto a dimensão vertical pressupõe uma 
ação entre desiguais - cidadãos X representantes - a dimensão horizontal pressupõe uma relação entre iguais -“checks and balances” entre os poderes constituídos.

O’Donnell admite a fragilidade dos mecanismos de accountability vertical quando, embora admitindo as eleições como seu canal principal, reconhece que, pelo fato destas só ocorrerem de tempos em tempos, em adição à existência de sistemas partidários pouco estruturados, a alta volatilidade de eleitores e partidos, temas de políticas públicas pobremente definidos, e reversões políticas súbitas, a eficácia da accountability eleitoral torna-se bastante fragilizada. As eleições inevitavelmente têm característica de plebiscito: por mais bem informados que estejam os eleitores, a eleição permite apenas que ratifiquem ou rejeitem, de tempos em tempos, as decisões tomadas pelas equipes formadas por seus representantes, que competem e cooperam umas com as outras (BOBBIO, citado por PRZEWORSKI, 1998:66). Idéia semelhante encontra-se nos argumentos de Stark \& Bruszt (1998), quando reconhecem que o caráter epísódico da responsabilidade eleitoral proporciona aos políticos o espaço de manobra para levar a cabo o programa vencedor que haviam oferecido ao eleitorado e em Przeworski \& Stokes ao admitirem que "a votação retrospectiva que toma informações apenas no desempenho passado do candidato, não é suficiente para induzir os governos a atuarem responsavelmente" (PRZEWORSKI \& STOKES, citados por O’DONNELL 1998:29).

A eficácia dos demais mecanismos de accountability vertical - as reivindicações sociais e atuação da mídia - também é questionada por O’Donnell (1998). Este autor considera que a mídia, agindo parcialmente, ao denunciar possíveis delitos, nomeando os supostos responsáveis, contribuem para que algumas autoridades corruptas sejam poupadas, enquanto inocentes são condenados pela opinião pública e que as reivindicações sociais dependem fundamentalmente das ações que as agências estatais autorizadas tomem para investigação e punição dos delitos.

Com referência à dimensão horizontal, O'Donnell considera que sua efetividade depende não apenas de agências isoladas lidando com questões específicas, mas com uma rede dessas agências, vez que normalmente as decisões são tomadas pelos tribunais ou, em caso de impeachment, dos legisladores. O’Donnell reconhece ainda a possibilidade de violação da accountability horizontal através da usurpação ilegal da autoridade de uma agência 
estatal por outra e da corrupção, que consiste na obtenção de vantagens ilícitas por uma autoridade pública para si ou para aqueles de alguma maneira ligados a ela. Figueiredo (2001) considera que, embora divergentes nas explicações para a fraca físcalização dos governos pelos legislativos, tribunais e outras agências criadas para este fim, os analistas políticos parecem ter chegado a um consenso sobre a deficiência da accountability horizontal nos sistemas presidencialistas da América Latina. Reconhece a autora que a concentração de poder legislativo no Executivo tornou-se um traço comum nesses regimes.

Stark \& Bruszt (1998) destacando a importância dos mecanismos de accountability afirmam que, contrariamente a crença convencional de que executivos não limitados têm mais autoridade para executar reformas, autoridade e responsabilidade não são contraditórios. Através de estudo comparativo de vários países da Europa Central, esses autores concluem que existe uma correlação negativa entre autoridade executiva concentrada e coerência nas políticas, ou seja, as políticas são coerentes e sustentáveis onde as estruturas institucionais colocam fortes limites à autoridade do executivo. Esses autores sugerem ainda que a responsabilidade horizontal - entre instituições internas ao Estado defendida por O’Donnell avance para o que eles denominam de "responsabilidade em escopo", através da inclusão de outras instituições políticas, notadamente outros agentes organizados da sociedade, em redes de responsabilidade. Nesse aspecto, Campos (1990:35) chama a atenção para o fato de que, em termos ideais, a tarefa de controlar não pode ficar nas mãos do Estado, posto que esta se constitui numa prerrogativa da cidadania organizada

Sobre essa inclusão, vale destacar que Przeworski (1998:67), admitindo que, ainda que todas as instituições democráticas clássicas estejam funcionando bem, elas não são suficientes para garantir a accountability e para capacitar os cidadãos a obrigarem os governos a cumprir com o seu dever, pois estes sempre disporão de informação privada sobre seus objetivos e sobre as relações entre as políticas e seus resultados, também sugere a criação de instituições independentes de outros órgãos do governo e que ofereçam aos cidadãos as informações necessárias para que estes aperfeiçoem sua avaliação a posteriori dos atos do governo, e não apenas dos resultados. Já para Schmitter (1999:59), dado que a noção de accountability horizontal de O’Donnell inclui apenas os agentes estatais, sugere que um outro tipo de accountability pode ser concebido para abrigar as instituições não estatais: a accountability oblíqua. 
Sobre o estabelecimento de mais uma dimensão de accountability convém destacar que Schedler (1999) considera que, dada à assimetria entre atores estatais e não-estatais, é fictício um cenário em que o controle de poder é perfeito e alerta para o fato de que as associações civis, embora representem poderes fáticos, nunca se igualam ao Estado, que detém o poder de monopólio da violência legítima e posição privilegiada como fonte de lei, concordando, dessa maneira com O’Donnell para quem o abrigo de tais instituições independentes é a dimensão vertical da accountability, não havendo, portanto, necessidade de criação de mais uma dimensão.

Completando esse breve estudo vale a pena ainda acrescentar que a noção de accountability política, para Schedler, possui caráter bidimensional: a) a capacidade de resposta dos governos, isto é, a obrigação dos detentores de mandatos públicos informarem e explicarem os seus atos - answerability e b) a capacidade das agências de impor sanções e perda de poder para aqueles que violarem os deveres públicos - enforcement.

Construindo uma concepção radial da accountability, este autor identifica nesta três questões, que podem ou não estar juntas para que existam atos de accountability, quais sejam: informação, justificação e punição. Nessa concepção, as duas primeiras questõesinformação e justificação - remetem à answerability, e a última - punição - à capacidade de enforcement. Accountability política implica, portanto, mais do que geração de dados e interação de argumentos, mas também a possibilidade de punir comportamento inadequado. Exercícios de accountability que expõem delitos sem a imposição de consequiências materiais aparecerão, segundo este autor, como fracas e diminuídas formas de accountability.

\section{A accountability no Brasil}

Considerando, portanto, que o conceito de accountability está intimamente relacionado com a questão dos direitos dos cidadãos e deveres dos administradores públicos, nos Estados cuja democracia tem sido adjetivada como delegativa (O’Donnell:1991) o baixo grau ou até a completa inexistência de accountability é um traço distintivo.

Campos (1990:35-37) destaca que não haverá condição para a accountability enquanto o povo se definir como tutelado e o Estado como tutor. Ademais, considera ainda esta autora, 
a virtual ausência do conceito de accountability no Brasil decorre da sua pobreza política, uma vez que as pessoas optam por esperar que o Estado defenda e proteja os interesses não organizados, ao invés de atuar na organização para agregação de seus próprios interesses, ou para enfrentamento do poder do Estado. Tais características são típicas das democracias delegativas. Nesse sentido, consideramos que vale a pena verificar se a aprovação da Lei de Responsabilidade Fiscal contribui para a ampliação do grau de accountability vigente no Brasil.

Os mecanismos de accountability vertical e horizontal existentes no Brasil têm sido qualificados pela literatura como deficientes. Pode-se pressupor que a correta aplicação da Lei de Responsabilidade Fiscal possa contribuir para a redução da deficiência de tais mecanismos.

Para Campos (1990), por exemplo, embora essencial, o processo eleitoral, por si só, não é ágil bastante para salvaguardar o interesse público, uma vez que muitos eleitores trocam votos por dinheiro e por empregos nos órgãos públicos, abdicando do direito de cobrar de seus candidatos programas que alterem a hegemonia de grupos tradicionalmente favorecidos; à imprensa tem faltado organização e autonomia para poder agir e reagir como instituição, pois fragmentada e subserviente a interesses e conveniências particulares não tem desempenhado o papel de vigilante, que geralmente lhe cabe nas sociedades politicamente avançadas. Falta credibilidade também ao poder legislativo, cujos “representantes" não sendo pressionados a cumprir as promessas de campanha, preocupamse apenas com os seus interesses pessoais e as conveniências de seus parentes e amigos e ao Judiciário dependente do Executivo até para obtenção de recursos orçamentários. Este cenário de debilidade das instituições em adição ao baixo nível de organização da sociedade civil é o que explica, segundo esta autora, a má qualidade do processo de informações entre governo e sociedade e permitiu a supremacia do Executivo federal sobre os níveis estaduais e municipais, bem como sobre os poderes Legislativo e Judiciário no Brasil. Nas palavras dessa autora “imune a controles externos, a burocracia pública é corrupta e ineficiente, enquanto os cidadãos continuam sem qualquer proteção contra as decisões arbitrárias" (CAMPOS, 1990:42). 
Na análise efetuada por Figueiredo (2001), a deficiência dos mecanismos de accountability horizontal no Brasil, decorre do padrão de formação de governos de coalizão aliado ao fato de que a Constituição brasileira concede ao executivo fortes poderes legislativos e de agenda, tais como: exclusividade de iniciativa na introdução de legislação administrativa, orçamentária e fiscal; poder de pedir urgência para as leis que apresenta; autoridade delegada de decreto; e autoridade para editar decretos, com força de lei e de vigência imediata, as Medidas Provisórias, e, não menos importante, que os regulamentos do Congresso concedem aos líderes de partidos amplo controle sobre o processo legislativo definição de pauta e poder de representar a bancada. Cumpre acrescentar que dentre todas estas prerrogativas, o poder de editar medidas provisórias com força de lei, é o instrumento que mais concentra poderes de agenda nas mãos do presidente (ANASTASIA \& MELO, 2002; AMORIM NETO \& TAFNER, 2002) e, neste sentido, à medida que aumenta a capacidade de controle do Executivo sobre a coalizão governista, diminui a do Congresso para fiscalizar o Executivo, possibilitando ao governo funcionar como se houvesse uma fusão de poderes (FIGUEIREDO, 2001:02). Esses mencionados recursos institucionais permitem aos governos aumentar a coesão das coalizões que os apóiam e promover ações coordenadas, capacitando-os a evitar ou controlar as ações de fiscalização do Congresso, especialmente as atividades de investigação. Nesse contexto, a eficácia da accountability horizontal passa a depender da atuação dos mecanismos da accountability vertical, como a mobilização da opinião pública pela imprensa e por grupos organizados (FIGUEIREDO, 2001:02-03). Por outro lado, como "os mecanismos de cobrança horizontal obrigam o governo a justificar e defender suas ações perante outros órgãos de governo, servem também para informar os cidadãos" (PRZEWORSKI, 1996:32 citado por FIGUEIREDO, 2001), a autoridade concentrada no executivo reduz a transparência das decisões públicas, privando os cidadãos da chance de obter informações sobre políticas, reduzindo assim sua capacidade de controlar as ações do governo. Com referência à debilidade dos mecanismos de accountability horizontal no Brasil, Anastasia \& Melo (2002) também afirmam que a concentração dos poderes de agenda e de veto nas mãos do Executivo, em uma das Câmaras, e/ou nas mãos da bancada governista, o acentuado grau de centralização política no nível nacional e a assimetria informacional entre os atores centrais, cidadãos, líderes de coalizão e legisladores, favorecem a autonomia das burocracias públicas, enfraquecendo, 
portanto, a responsabilização do Executivo por controle do Legislativo. Lecionam esses autores, no caso brasileiro, como, de resto, em qualquer sistema presidencialista, os instrumentos de accountability horizontal incluem, além dos mecanismos de controles mútuos entre os poderes Executivo e Legislativo, aqueles referidos à fiscalização de ambos pelo Poder Judiciário e pelo Ministério Público. Acrescentam ainda os citados autores que literatura tem se apoiado no conceito de presidencialismo de coalizão (ABRANCHES, 1988) para caracterizar o padrão de relacionamento entre os poderes Executivo e Legislativo no Brasil. Esse arranjo institucional, para esses analistas, embora produza estabilidade política, limita a accountability horizontal e diminui a densidade democrática a representação, vez que dificulta aos agentes, especialmente situados na oposição, a vocalização de suas preferências e controle dos atos e omissões dos governantes. Para Nicolau (2002), como nos governos de coalizão as políticas públicas são compartilhadas, a capacidade de o eleitor atribuir a um único partido a responsabilidade pelas políticas implementadas é bastante reduzida, o que equivale a dizer que nesse tipo de governo onde não há clareza de responsabilidade, o controle dos cidadãos sobre o legislativo, também é limitado.

No argumento desenvolvido por Anastasia \& Melo (2002), quando a assimetria informacional entre os atores diminui, o desempenho dos mecanismos de accountability horizontal e vertical reforça-se mutuamente. Dito de outra forma, o bom ou o mau desempenho dos mecanismos de uma dimensão incide positivamente ou negativamente sobre a outra dimensão e vice-versa. Assinalam ainda esses autores que "as possibilidades de mobilização eficiente dos procedimentos eleitorais para fins do exercício da responsabilização política crescem na medida em que diminui a assimetria informacional entre representantes e representados", uma vez que "o poder legislativo terá mais incentivo a atuar como órgão de controle sobre o poder executivo na medida em que seja, ele próprio, passível de controle pelos cidadãos” (SHUGART, MORENO \& CRISP citados por ANASTASIA \& MELO, 2002:29).

As variáveis que afetam a constituição da representação política e o exercício da accountability vertical e horizontal no Brasil, notadamente os sistemas eleitoral e partidário no primeiro caso, e as regras constitucionais e regimentais que distribuem poderes de agenda e de veto entre os poderes Executivo e Legislativo no segundo, são examinadas por 
esses pesquisadores que argumentam que as opiniões e os interesses do eleitorado terão maiores chances de incidir sobre a ação dos representantes eleitos se o Poder Legislativo se constituir enquanto espaço institucional de expressão política das diferentes minorias e se existirem dispositivos constitucionais e regimentais capazes de permitir a participação institucionalizada dos cidadãos, nos interstícios eleitorais. Tais sistemas, para esses autores, exercem forte impacto sobre a constituição do poder legislativo, uma vez que é do sistema partidário a função de definir o número e perfis de agentes disponíveis para os cidadãos, e do sistema eleitoral encorajar a eleição de maiorias legislativas ou favorecer uma equitativa representação dos múltiplos partidos existentes.

Para esses autores, embora se reconheça fragilidade nas organizações partidárias brasileiras, inclusive nos vínculos destas com o eleitorado, alta incidência das migrações e profusão de legendas de aluguel, "não se pode afirmar que o sistema partidário torne artificial a expressão da competição política nacional", além disso, "em que pese o alto grau de fracionamento do sistema partidário, as interações ocorridas no seu interior têm sido do tipo moderada, não se verificando a presença de partidos relevantes claramente antisistema nem de intensidades de preferências tão altas que inviabilizem a prática de negociação e da barganha" (ANASTASIA \& MELO, 2002:37).

O sistema eleitoral brasileiro possui características bastante particulares: lista aberta, possibilidade de o eleitor votar apenas na legenda, possibilidades de os partidos fazerem coligações, grande número de partidos e candidatos concorrendo. Tudo isso provoca, segundo a análise desse pesquisador uma distorção entre o conjunto de preferências manifestas pelo eleitorado e a real distribuição de cadeiras entre os partidos, visto que há evidências indiretas de que o eleitor no Brasil escolhe, na maioria das vezes, o seu candidato sem levar em conta o partido no qual este está filiado, o chamado voto personalizado, e a suposição do desconhecimento por parte do eleitor de como funciona o mecanismo de transformação de votos em cadeiras, visto que aqueles, independentemente das opções de escolhas conferidas ao eleitor, são contabilizados em termos partidários, adotando-se posteriormente algum mecanismo de transferência no interior da lista como forma de se chegar aos eleitos (NICOLAU, 2002; ANASTASIA \& MELO, 2002). Como lembra Nicolau (2002), no Brasil partidos coligados podem eleger candidatos mesmo sem atingir o quociente eleitoral, candidatos podem aumentar sua votação e não se reeleger, 
enquanto outros podem obter número de votos menor e mesmo assim garantir sua reeleição. Ademais, o representante eleito depara-se com um cenário no qual o atingimento dos compromissos assumidos com os eleitores somente será possível se estiverem compatíveis com as preferências dos líderes partidários, uma vez que são a estes que, conforme dito anteriormente, são conferidos, pelos regulamentos das Casas Legislativas, o poder de definição de pauta e de representação da bancada.

Tudo isso para concluir que o eleitor brasileiro teria mais facilidade de acompanhar o processo legislativo se designasse, como seu agente, o partido e não o candidato individualmente e que os mecanismos de accountability vertical, notadamente as eleições, momento privilegiado para punir ou recompensar os responsáveis pelo governo: bons governantes seriam reconduzidos ao poder, enquanto os ineficientes seriam afastados (NICOLAU, 2002), não tem sido capaz de incidir sobre os processos de accountability horizontal.

Ainda sobre a participação institucionalizada dos cidadãos nos interstícios eleitorais, cumpre informar que Anastasia \& Melo (2002) reconhecem que, nos últimos anos, tanto o Executivo quanto o Legislativo, no plano federal, tem tomado iniciativas que ampliam a possibilidade de intervenção dos cidadãos no processo decisório, de forma contínua, destacando no que se refere às iniciativas do poder Executivo: 1.a aprovação da Lei de Responsabilidade Fiscal; 2. O funcionamento do SIAFI, sistema considerado como principal instrumento de administração orçamentária e financeira da União, por meio do qual são obtidas as informações que subsidiam o balanço geral da União e os relatórios de execução do orçamento e de administração financeira, que compõe, a demonstração das contas apresentadas ao Congresso Nacional pelo Presidente da República; 3. O acesso, via Internet, ao processo de transferências dos FPE e FPM (respectivamente Fundos de Participação dos Estados e Fundos de Participação dos Municípios); 4. A disponibilização pública das informações sobre a implementação e avaliação contínua do plano plurianual, através do site do ministério do Planejamento, Orçamento e Gestão e das informações necessárias à fiscalização rotineira e detalhada da execução do Orçamento da União através da Internet pelo PRODASEN, sistema de processamento de dados do Senado; e 5. A criação da Corregedoria Geral da União, com atribuições de correção, controle interno, auditoria pública e de ouvidoria geral no âmbito do Poder Executivo Federal, objetivando 
dar o necessário andamento às representações ou denúncias fundamentadas, relativas à lesão ou ameaça de lesão ao patrimônio público (ANASTASIA \& MELO, 2002:40-41). Tais iniciativas têm, segundo esses pesquisadores, facilitado o acesso à informação sobre o exercício do governo no Brasil, uma vez que os parlamentares, de posse de tais recursos, podem trazer para o debate público eventuais problemas detectados e vice-versa.

Já quanto aos avanços nas relações entre o Legislativo, notadamente entre o Congresso Nacional, e os cidadãos, os autores destacam: 1. A comunicação direta com o cidadão a partir do funcionamento das TVs Câmara e Senado, bem como das Rádios Câmara e Senado; 2. A disponibilização, através dos respectivos sites de informação detalhada sobre o funcionamento de ambas as casas; 3. A criação, em 2001, da Ouvidoria da Câmara dos Deputados. No Senado, a ouvidoria é feita através de um serviço tipo 0800; 4 . A criação da Comissão de Legislação Participativa, também em 2001, com poderes para acolher e transformar em proposição legislativa sugestões apresentadas por associações e órgãos de classe, sindicatos e entidades organizadas da sociedade civil ou pareceres técnicos, exposições e propostas oriundas de entidades científicas e culturais; e 5. A modificação do Artigo 53 da Constituição Federal, processada em Dezembro de 2001, dando nova redação à questão da imunidade parlamentar e tornando os deputados e senadores passíveis de processo pelo Supremo Tribunal Federal sem a necessidade de licença prévia da Casapodendo esta, no entanto, sustar a ação por maioria de votos em um prazo de 45 dias. Entretanto, mesmo reconhecendo a importância de tais instrumentos, esses autores assinalam que estes são insuficientes para que se possa afirmar que o eleitor no Brasil esteja em condições de instruir ou responsabilizar os seus representantes, dado que o processo de tomada de decisão envolve uma série de atores com alguma capacidade de interferência, um Executivo com poderes de legislar e vetar, duas casas legislativas com capacidade de modificação recíproca às iniciativas, o multipartidarismo e instrumentos judiciais que são com freqüência chamados a resolver questões de ordem política (ANASTASIA \& MELO, 2002:44-45).

Constata-se assim a existência de um avanço gradual no processo de institucionalização da accountability no Brasil. Neste processo observa-se que a aprovação da Lei de Responsabilidade Fiscal tem ocupado relevante espaço nos estudos dedicados ao tema, 
sendo, por isso, escolhida para apresentação e análise detalhada nesse paper, conforme segue.

\section{A Lei de Responsabilidade Fiscal}

Regulamentando, doze anos depois, o disposto no artigo 163 da Constituição Federal, que estabelece que "lei complementar disporá sobre (I) Finanças Publicas", foi aprovada em 04 de maio de 2000 a Lei Complementar $n^{\circ}$ 101/2000, popularmente conhecida como Lei de Responsabilidade Fiscal. Com alto índice de votos favoráveis - 385 votos a favor, 86 contra e 04 abstenções - a Lei de Responsabilidade Fiscal (doravante LRF) está estruturada por setenta e cinco artigos e promove uma mudança institucional no trato com o dinheiro público. Constituindo-se no principal instrumento regulador das contas públicas no Brasil, espera-se que a sua correta aplicação fortaleça o processo de accountability no Brasil.

No entendimento de Vignoli (2002) trata-se de uma das mais rigorosas legislações a respeito deste tema. De fato, o estudo comparativo realizado por Oliva (2001) entre as recentes iniciativas de sete países, incluindo o Brasil, para o estabelecimento de regras fiscais, confirma essa tese. Oliva (2001) admite ainda que implementar a responsabilidade fiscal não é uma tarefa fácil, fato alertado também por Dias Filho (2003:03) quando este afirma que para o seu equacionamento depende da mobilização de recursos humanos, tecnológicos, financeiros e principalmente da capacidade de enfrentar resistências de ordem política e cultural. Porém, no caso específico brasileiro, além dos méritos técnicos da Lei, Oliva (2001) reconhece que o processo público de consulta realizado e o consenso político obtido atuam como elementos chaves para a sustentabilidade dessa reforma estrutural.

O equilíbrio fiscal é apontado por Dias Filho (2003:03) como necessário para a superação de graves problemas que afetam o bem estar social, tais como inflação, taxas de juros restritivas, desemprego e insuficiência de serviços públicos como saúde, segurança e educação. Entretanto, para este autor, a questão não se resume apenas a arrecadar mais e gastar menos. Se tudo dependesse de arrecadar mais, Dias Filho (2003) chama a atenção para o fato de que sendo a carga tributária brasileira uma das mais altas do mundo, chegando a ultrapassar 36\% do PIB em 2002, o Brasil seria um dos últimos países a experimentar os efeitos de um déficit fiscal. Portanto, para este autor, é necessário explorar 
com eficiência e justiça todo o potencial tributário disponível em cada ente da federação, o que naturalmente vai exigir um aparelho eficiente na atuação da gestão tributária capaz de aumentar o número de contribuintes, cobrando menos de cada um e mais do conjunto. Quanto ao controle dos gastos, este autor alerta que, além de fechar as comportas do desperdício, é preciso levar em conta que gastar pouco não significa necessariamente gastar bem, asseverando que:

Não se trata apenas de economizar cada centavo do erário, mas principalmente de aplicar bem os recursos existentes para que eles gerem mais benefícios ao menor custo possível para a sociedade. Um pouco mais que se aplique adequadamente em prevenção de doenças e em educação, por exemplo, pode evitar gastos públicos significativos no futuro e, assim, aliviar as pressões que recaem sobre o sistema tributário. Para se ter uma idéia, estima-se que cada real investido em saneamento pode proporcionar uma economia de quatro no orçamento da saúde.

O pensamento deste autor alinha-se bem com o de Batista (1995:121) quando este, embora reconhecendo que a âncora fiscal é fundamental para o restabelecimento da confiança na capacidade governamental de gerir a moeda, considera que na proposta neoliberal a necessária distinção entre despesas correntes e de investimentos, por razões talvez mais ideológicas do que econômica, não é levada em conta, visto que as últimas podem e devem, segundo este autor, ser financiadas por empréstimos, de preferência internos a externos. Assim, também para este autor:

O que não se deve é, em nome de um falso conceito de responsabilidade fiscal, buscar equilíbrio em nível tão baixo de receitas e despesas que inviabilize o desempenho pelo Estado de funções essenciais de incentivador do desenvolvimento, de promotor do pleno emprego e da justiça social. 


\section{Análise e aplicação da Lei de Responsabilidade Fiscal}

De total abrangência, uma vez que se estende à União, aos Estados, ao Distrito Federal e aos Municípios, à administração direta e indireta, e em cada uma dessas esferas de governo, aos poderes Executivo, Legislativo e Judiciário, bem como ao Ministério Público, a LRF está apoiada em quatro eixos, quais sejam planejamento, transparência, controle e responsabilização (KHAIR, 2001) e define no seu parágrafo primeiro do artigo primeiro a responsabilidade na gestão físcal como sendo a "ação planejada e transparente, em que se previnem riscos e corrigem desvios capazes de afetar o equilíbrio das contas públicas, mediante o cumprimento de metas de resultados entre receita e despesas e a obediência a limites e condições no que tange a renúncia de receita, geração de despesas com pessoal, da seguridade social e outras, dívidas consolidada e mobiliária, operações de crédito, inclusive por antecipação de receita, concessão de garantia e inscrição em Restos a Pagar" (grifos nossos).

\section{Do planejamento}

Expresso literalmente no texto da LRF, o planejamento figura, por assim dizer, como o ponto de partida para o seu entendimento. Contando com vinte e oito artigos que tratam direta ou indiretamente desse tema, a LRF cria novas informações, metas, limites e condições para a renúncia de receita, para a geração de despesas, inclusive com pessoal e de seguridade, para assunção de dívidas, para a realização de operações de crédito, incluindo antecipação de receita orçamentária (ARO), e para a concessão de garantias, o que evidencia que a disciplina fiscal somente poderá ser alcançada com o adequado planejamento das ações de governo e da execução orçamentária (VIGNOLI, 2002).

Nesse sentido, as três peças orçamentárias constitucionalmente instituídas, o Plano Plurianual, a Lei de Diretrizes Orçamentárias e, em especial, a Lei Orçamentária Anual, revestem-se de significativa importância. Como se sabe, o Plano Plurianual (PPA) é a peça que estabelece os programas e ações de governo com horizonte temporal mais largo quatro anos; já à Lei de Diretrizes Orçamentária (LDO) cabe o estabelecimento das prioridades, metas e premissas básicas norteadoras da elaboração do orçamento anual; e, 
finalmente, à Lei Orçamentária Anual (LOA) a elaboração detalhada da programação a ser realizada em determinado exercício financeiro ( $1^{\circ} \mathrm{de}$ janeiro a 31 de dezembro).

No entendimento de Vignoli (2002: 15-17) desde a Lei 4.320/64, que estatui normas gerais de direito financeiro para a elaboração e controle dos orçamentos e balanços da União, dos Estados, dos Municípios e do Distrito Federal, já existem as condições para a efetiva integração entre planejamento, programação e orçamento no Brasil, fato que também é reconhecido por Khair (2001) quando este afirma que, se a referida Lei já tivesse sido observada, o equilíbrio das contas públicas há muito já poderia ter ocorrido. De fato, a alínea "b" do artigo 48 da Lei 4.320/64 estabelece como um dos objetivos que, quando da fixação de cotas da despesa para cada unidade orçamentária, o Poder Executivo deverá manter, na medida do possível, o equilíbrio entre a receita arrecadada e a despesa realizada, de modo a reduzir ao mínimo eventuais insuficiências de tesouraria. Entretanto, em que pese os instrumentos orçamentários (PPA, LDO e LOA) serem absolutamente interdependentes, tradicionalmente o orçamento público, ao invés de se constituir em um verdadeiro instrumento diretor de curto prazo, constituía-se em um documento meramente formal a ser encaminhado para atender aos preceitos estabelecidos pela legislação em vigor. Com a obrigação agora imposta pela LRF, espera-se, segundo Vignoli (2002:16) que tais hábitos enraizados, pouco saudáveis e muitas vezes prejudiciais ao interesse público deverão ser substituídos por condutas adequadas de gestão responsável no trato dos negócios públicos, uma vez que esta, além de consolidar, aprimora esses três pilares do planejamento do setor público brasileiro. Assim é que, a partir de então, a LDO deixa de ser um instrumento totalmente desconectado do PPA e da LOA para constituir-se numa referência para o efetivo planejamento das ações de governo, e, ao estabelecer as metas e prioridades para o exercício subsequiente, passa a efetuar a necessária ligação entre o PPA e a LOA. Para VIGNOLI (2002), isso significa que o processo de planejamento se inicia bem antes da efetiva elaboração do orçamento.Tanto é que, a não ser por meio de Lei específica que autorize a sua inclusão no PPA, a LOA não poderá destinar recursos para qualquer investimento cuja execução ultrapasse um exercício financeiro, sem que haja previsão na LDO e no PPA.

Além de procedimentalizar a conexão e a articulação entre tais instrumentos (LINO, 2001:31), a LRF introduziu a necessidade de elaboração dos Anexos de Metas Fiscais e de 
Riscos Fiscais, os quais deverão integrar a LDO. No Anexo de Metas Fiscais deverá ser discriminadas as metas de arrecadação e de gastos e, da comparação entre eles, a previsão de resultados primário ${ }^{\mathrm{i}}$ e de resultado nominal ${ }^{\mathrm{ii}}$. Claro está, portanto, que meta físcal é o que se estima arrecadar e, com base nessa estimativa, o que se gastar (VIGNOLI, 2002). Já no Anexo de Riscos Fiscais deverão estar discriminadas e avaliadas as possibilidades de se incorrer em pagamentos para os quais não se possui convicção plena (por exemplo, as decisões judiciais), bem como a não realização de receitas previstas. Constata-se, portanto, que a preocupação constante na LRF é buscar o equilíbrio entre receitas e despesas. Neste aspecto, concorda-se mais uma vez com a afirmação de VignoliI (2002: 52), de que para a LRF o Déficit não pode existir.

Outro relatório estabelecido pela LRF, objetivando o controle de observância dos limites e condições, é o Relatório da Gestão Fiscal. De acordo com o exposto no seu artigo 54, até o final dos meses de maio, setembro e fevereiro, os titulares dos Poderes, Tribunais de Contas e do Ministério Público deverá publicá-lo, com amplo acesso ao público. Este relatório deverá conter o comparativo com os limites de que trata a LRF, a indicação das medidas corretivas adotadas ou a adotar, se ultrapassado qualquer dos limites, além de demonstrativos, no último quadrimestre, da disponibilidade de caixa em 31 de dezembro e da inscrição em restos a pagar e do cumprimento dos prazos das AROs (antecipação de receitas orçamentárias). O quadro abaixo ilustra os limites estabelecidos pela LRF:

\footnotetext{
${ }^{\mathrm{i}}$ Resultado Primário corresponde à diferença entre as receitas arrecadadas e as despesas empenhadas, não considerando o pagamento do principal e dos juros da dívida. Se o total das receitas for maior que o total das despesas temos uma situação de Superávit Primário. Na situação inversa, Déficit Primário (VIGNOLI, 2002:51-52).

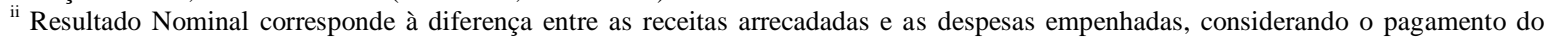
principal e dos juros da dívida. Se o total das receitas for maior que o total das despesas temos uma situação de Superávit Nominal. Na situação inversa, Déficit Nominal (Idem).
} 


\section{Quadro 1 \\ Limites Estabelecidos na LRF}

\begin{tabular}{|c|c|}
\hline Serviço da dívida & $13 \%$ da receita líquida real \\
\hline Dívida consolidada & 1,2 vezes a receita corrente líquida \\
\hline Novação ou refinanciamento de dívida & Proibida \\
\hline $\mathrm{ARO}$ & $\begin{array}{l}\text { Proibida entre } 10 \text { de dezembro e } 9 \text { de janeiro do ano } \\
\text { seguinte e no último ano de mandato. }\end{array}$ \\
\hline Despesa de pessoal & $\begin{array}{l}60 \% \text { da receita corrente líquida, sendo } 6 \% \text { para o } \\
\text { Legislativo e } 54 \% \text { para o Executivo. }\end{array}$ \\
\hline Aumento da despesa de pessoal & Proibido se não previsto na LDO e na LOA \\
\hline Despesa com inativos & $12 \%$ da receita corrente líquida \\
\hline $\begin{array}{l}\text { Aumento da despesa de pessoal no segundo semestre } \\
\text { do final do mandato }\end{array}$ & Proibido \\
\hline Se a despesa de pessoal exceder a $95 \%$ do limite & Proibido aumento da despesa de pessoal \\
\hline Operações de crédito & Não podem superar as despesas de capital \\
\hline $\begin{array}{l}\text { Despesas que constituam obrigações constitucionais e } \\
\text { legais, inclusive as destinadas ao pagamento do } \\
\text { serviço da divida. }\end{array}$ & $\begin{array}{l}\text { Sem limite para as definidas na LDO, desde que } \\
\text { respeitadas as restrições da LRF. }\end{array}$ \\
\hline Inscrições em restos a pagar & $\begin{array}{l}\text { Só se inferior à disponibilidade de caixa no último } \\
\text { ano do mandato. }\end{array}$ \\
\hline $\begin{array}{l}\text { Contrair obrigação de despesa nos últimos dois } \\
\text { quadrimestres do mandato. }\end{array}$ & $\begin{array}{l}\text { Proibida se não puder ser paga com recursos do } \\
\text { mandato. }\end{array}$ \\
\hline $\begin{array}{l}\text { Transferências voluntárias relativas a ações de } \\
\text { educação, saúde e assistência social. }\end{array}$ & Sem limite. \\
\hline Novos projetos & $\begin{array}{l}\text { Só após adequadamente atendidos aqueles em } \\
\text { andamento e contempladas as despesas de } \\
\text { conservação do patrimônio público. }\end{array}$ \\
\hline $\begin{array}{l}\text { Renúncia de receita (anistia, remissão, subsídio, } \\
\text { isenção, redução de alíquota e/ou base de cálculo) }\end{array}$ & $\begin{array}{l}\text { Deverá ser acompanhada de estimativa de impacto } \\
\text { orçamentário-financeiro no exercício em que deva } \\
\text { iniciar a sua vigência e nos dois subseqüentes, bem } \\
\text { como de medidas de compensação. }\end{array}$ \\
\hline $\begin{array}{l}\text { Despesa obrigatória de caráter continuado (superior a } \\
\text { dois anos). }\end{array}$ & $\begin{array}{l}\text { Deverá ser acompanhada de estimativa de impacto } \\
\text { orçamentário-financeiro no exercício em que deva } \\
\text { iniciar a sua vigência e nos dois subseqüentes, bem } \\
\text { como a origem dos recursos para o seu custeio. }\end{array}$ \\
\hline
\end{tabular}

Fonte: KHAIR (2001:85). Com adaptações. 


\section{Da transparência}

Ao contemplar a criação de uma série de relatórios e demonstrativos, objetivando comparar o que foi planejado (PPA, LDO e LOA) com a execução orçamentária (prestação de contas e o respectivo parecer prévio emitido pelo Tribunal de Contas, relatório resumido da execução orçamentária e o relatório da gestão fiscal), permitindo também conhecer as medidas adotadas pelos gestores públicos para assegurar o equilíbrio das contas públicas, constata-se que o famoso ciclo da Gestão pela Qualidade Total - planejar, executar, verificar e atuar - está presente na LRF. Estabelecendo no seu artigo 48 que tais instrumentos serão objetos de ampla divulgação, inclusive em meios eletrônicos de acesso público e também o incentivo à participação popular e realização de audiências públicas durante os processos de elaboração e discussão dos planos, lei de diretrizes orçamentárias e da lei orçamentária anual, a LRF introduz, segundo Vignoli (2002) o real entendimento de transparência da gestão fiscal. Para este autor, como tem sido comum a simples publicação dos atos oficiais, das leis relativas aos orçamentos e dos relatórios exigidos pela legislação vigente, restringindo-se, na maioria das vezes, ao mínimo necessário, a utilização do termo transparência no texto da LRF evidencia o desejo de estabelecer com rigor a distinção entre o termo utilizado e aquilo que a prática tem referendado.

Ademais, com a determinação de se assegurar a transparência por meio da participação popular no processo de elaboração dos planos, LDO e LOA, literalmente contida no parágrafo primeiro do referido artigo, a instituição de mecanismos de interação sociedade / governo, a exemplo do orçamento participativo, passa a ser fortemente estimulada. Assevera Vignoli (2002) que a discussão dos investimentos contemplados obrigatoriamente no PPA implicará também a discussão do custeio desses investimentos, resultando, no médio prazo, na participação popular da definição de parcela cada vez mais expressiva do orçamento. Considera ainda o referido autor que o sucesso do orçamento participativo depende também da participação popular durante a execução orçamentária, visto que é nesta fase que se obtém a certeza quanto ao cumprimento do que foi anteriormente definido. É assim que a transparência e a continuidade do processo fica assegurada. 


\section{Do controle}

Conseqüência natural da transparência e da qualidade das informações, o controle das contas públicas com o advento da LRF foi bastante aprimorado. Os controles clássicos ou tradicionais da accountability horizontal são citados no artigo 59 quando este estabelece que a fiscalização das normas contidas na referida Lei Complementar será exercida pelo Poder Legislativo, diretamente ou com o auxílio dos Tribunais de Contas, pelo sistema de controle interno de cada Poder e pelo Ministério Público. Nesse aspecto, os pareceres prévios emitidos pelos Tribunais de Contas assumem grande relevância, pois funcionarão também como instrumento de transparência da gestão fiscal. Para Vignoli (2002), tais julgamentos poderão assegurar que a norma técnica e legal prevaleça sobre os critérios obscuros que muitas vezes acabam norteando a apreciação do parecer prévio do Legislativo.

Convém observar ainda que a LRF fixou o prazo de sessenta dias após o recebimento das prestações de contas para que os Tribunais de Contas emitam o parecer prévio das capitais e municípios que tenham mais de duzentos mil habitantes, impedindo inclusive o recesso dos tribunais enquanto existirem contas pendentes de pareceres prévios. Tal medida evita o atraso na apreciação das contas dos gestores de recursos públicos.

Além disso, os Tribunais de Contas deverão alertar os Poderes ou órgãos sujeitos ao seu controle quando constatarem que a realização da receita poderá não comportar o cumprimento das metas de resultado primário ou nominal estabelecidas no Anexo de Metas Fiscais; que o montante dos gastos com pessoal e os níveis de endividamento ultrapassou noventa por cento do limite; que os gastos com inativos e pensionistas se encontram acima do limite definido em lei; que houve comprometimento dos custos ou dos resultados dos programas de governo e que existem indícios de irregularidades na gestão orçamentária.

Já no aspecto do controle social, aquele que é exercido pelos cidadãos em defesa de seus interesses, o incentivo à instituição de mecanismos de participação popular, a exemplo do orçamento participativo, assume grande relevância, pois, como bem lembra Campos (1990): 
Uma sociedade precisa atingir um certo nível de organização de seus interesses públicos e privados, antes de tornar-se capazes de exercer controle sobre o Estado. A extensão, qualidade e força dos controles são conseqüência do fortalecimento da malha institucional da sociedade civil. À medida que os diferentes interesses se organizam, aumenta a possibilidade de os cidadãos exercerem o controle e cobrarem do governo aquilo a que têm direito. Um desses mecanismos de controle seria a participação da sociedade civil na avaliação das políticas públicas, fazendo recomendações a partir dessa avaliação.

\section{Da responsabilização}

A responsabilização constitui num aspecto contundente da LRF e deverá ocorrer sempre que houver descumprimento das regras nela estabelecidas. Assim é que para assegurar a efetividade da LRF, foram criadas as sanções institucionais (aquelas que recaem sobre o ente público) e pessoais (que recaem sobre o agente que der causa ou infração administrativa) e através da Lei 10.028/00, de 19.10.00, denominada Lei de Crimes de Responsabilidade Fiscal, alterações foram processadas no Código Penal Brasileiro para garantir a responsabilização dos seus transgressores. O quadro ilustrativo elaborado por Khair (2001) e abaixo reproduzido, demonstra as punições fiscais que recaem sobre os que incorrem no descumprimento das regras estabelecidas na LRF:

\section{Quadro 2}

\section{Punições ao Descumprimento da LRF}

\begin{tabular}{|c|c|}
\hline INFRAÇÃO & PUNIÇÃO AO ENTE PÚBLICO \\
\hline $\begin{array}{l}\text { Não instituir nem efetuar a previsão e arrecadação de } \\
\text { todos os impostos de sua competência. }\end{array}$ & Vedadas as transferências voluntárias. \\
\hline $\begin{array}{l}\text { Não eliminar no prazo estabelecido o excedente da } \\
\text { despesa com pessoal. }\end{array}$ & $\begin{array}{l}\text { Vedadas, enquanto perdurar o excesso: as } \\
\text { transferências voluntárias, obtenção de garantia e } \\
\text { contratação de operações de crédito, ressalvadas a } \\
\text { destinada ao refinanciamento da dívida mobiliária e } \\
\text { as que visem à redução da despesa de pessoal. }\end{array}$ \\
\hline $\begin{array}{l}\text { Não se adaptar aos limites da despesa de pessoal no } \\
\text { prazo. }\end{array}$ & $\begin{array}{l}\text { Suspensão, enquanto perdurar o excesso, de todos os } \\
\text { repasses de verbas federais e estaduais. }\end{array}$ \\
\hline
\end{tabular}




\begin{tabular}{|c|c|}
\hline $\begin{array}{l}\text { Não eliminar no prazo o excedente da dívida } \\
\text { consolidada ou mobiliária e das operações de crédito. }\end{array}$ & $\begin{array}{l}\text { Proibida operação de crédito. O ente deverá obter } \\
\text { resultado primário necessário à recondução ao limite, } \\
\text { promovendo limitação de empenho. Vencido o prazo, } \\
\text { e enquanto perdurar o excesso, ficará sem } \\
\text { transferências voluntárias. As restrições aplicam-se } \\
\text { imediatamente se a dívida exceder ao limite no } \\
\text { primeiro quadrimestre do último ano de mandato. }\end{array}$ \\
\hline Não honrar a garantia & $\begin{array}{l}\text { Ficam condicionadas as transferências constitucionais } \\
\text { ao ressarcimento do pagamento. }\end{array}$ \\
\hline $\begin{array}{l}\text { Dívida que tiver sido honrada pela União ou por } \\
\text { Estado, em decorrência de garantia prestada. }\end{array}$ & $\begin{array}{l}\text { Suspensão de acesso a novos créditos ou } \\
\text { financiamentos até a total liquidação da mencionada } \\
\text { dívida. }\end{array}$ \\
\hline Operação de crédito realizada com infração da LRF. & $\begin{array}{l}\text { Enquanto perdurar a infração o ente não poderá } \\
\text { receber transferências voluntárias, obter garantia, } \\
\text { contratar operações de crédito, ressalvadas a } \\
\text { destinada ao refinanciamento da dívida mobiliária e } \\
\text { as que visem à redução da despesa de pessoal. }\end{array}$ \\
\hline $\begin{array}{l}\text { Descumprimento do prazo para enviar as contas à } \\
\text { União ou para a publicação do Relatório Resumido da } \\
\text { Execução Orçamentária ou do Relatório da Gestão } \\
\text { Fiscal. }\end{array}$ & $\begin{array}{l}\text { Até o envio, não receberá transferências voluntárias e } \\
\text { não contratará operações de crédito, exceto as } \\
\text { destinadas ao refinanciamento do principal atualizado } \\
\text { da dívida mobiliária. }\end{array}$ \\
\hline INFRAÇÃO - Lei 10.028/2000 & PUNIÇÃO AO AGENTE \\
\hline $\begin{array}{l}\text { Contratação irregular de operação de crédito ou se a } \\
\text { dívida consolidada ultrapassar o limite máximo } \\
\text { autorizado por lei. }\end{array}$ & Reclusão de 1 a 2 anos. \\
\hline $\begin{array}{l}\text { Inscrição irregular ou acima do limite de restos a } \\
\text { pagar. }\end{array}$ & Detenção de 6 meses a 2 anos. \\
\hline $\begin{array}{l}\text { Assunção irregular de obrigação nos últimos oito } \\
\text { meses de mandato. }\end{array}$ & Reclusão de 1 a 4 anos. \\
\hline Ordenação de despesa não autorizada & Reclusão de 1 a 4 anos \\
\hline Prestação de garantia graciosa & Detenção de 3 meses a 1 ano \\
\hline Não cancelamento de restos a pagar & Detenção de 6 meses a 2 anos \\
\hline $\begin{array}{l}\text { Aumento da despesa de pessoal no último semestre } \\
\text { do mandato }\end{array}$ & Reclusão de 1 a 4 anos \\
\hline $\begin{array}{l}\text { Oferta pública ou colocação de títulos irregulares no } \\
\text { mercado }\end{array}$ & Reclusão de 1 a 4 anos \\
\hline
\end{tabular}




\begin{tabular}{|c|c|}
\hline $\begin{array}{l}\text { CRIMES DE RESPONSABILIDADE DOS } \\
\text { PREFEITOS - Lei } 10.028 / 2000\end{array}$ & PUNIÇÃO \\
\hline $\begin{array}{l}\text { Deixar de ordenar, no prazo, a redução da dívida } \\
\text { consolidada; ordenar ou autorizar a abertura de } \\
\text { crédito em desacordo com os limites; deixar de } \\
\text { promover ou de ordenar a anulação de operação de } \\
\text { crédito com inobservância de limite, condição ou } \\
\text { montante; deixar de promover ou de ordenar a } \\
\text { liquidação integral de ARO até o encerramento do } \\
\text { exercício financeiro; ordenar ou autorizar } \\
\text { refinanciamento ou postergação de dívida contraída } \\
\text { anteriormente; captar recursos a título de antecipação } \\
\text { de receita de tributo ou contribuição cujo fato gerador } \\
\text { ainda não tenha ocorrido; ordenar ou autorizar a } \\
\text { destinação de recursos provenientes da emissão de } \\
\text { títulos para finalidade diversa da prevista na lei que a } \\
\text { autorizou; e realizar ou receber transferência } \\
\text { voluntária em desacordo com a lei. }\end{array}$ & $\begin{array}{l}\text { Perda do cargo, com inabilitação, por até cinco anos, } \\
\text { para o exercício de qualquer função pública. }\end{array}$ \\
\hline $\begin{array}{c}\text { INFRAÇÕES ADMINISTRATIVAS - Lei } \\
10.028 / 2000\end{array}$ & PUNIÇÃO AO AGENTE QUE DER CAUSA \\
\hline $\begin{array}{l}\text { Deixar de divulgar ou de enviar ao Poder Legislativo } \\
\text { e ao Tribunal de Contas o Relatório da Gestão Fiscal, } \\
\text { nos prazos e condições estabelecidos em lei; propor } \\
\text { Lei de Diretrizes Orçamentárias que não contenha as } \\
\text { metas fiscais na forma da lei; deixar de expedir ato } \\
\text { determinando limitação de empenho e movimentação } \\
\text { financeira, nos casos e condições estabelecidos em } \\
\text { lei; e deixar de ordenar ou de promover, na forma e } \\
\text { nos prazos da lei, a execução de medida para a } \\
\text { redução da despesa total com pessoal que houver } \\
\text { excedido à repartição do limite máximo por Poder. }\end{array}$ & $\begin{array}{l}\text { Trinta por cento dos vencimentos anuais, sendo o } \\
\text { pagamento da multa de sua responsabilidade pessoal. }\end{array}$ \\
\hline
\end{tabular}

Fonte: Adaptado de KHAIR (2001:87-89 


\section{Considerações Finais}

Conforme ficou evidenciado, a literatura qualifica os mecanismos brasileiros de accountability como deficientes. Tal deficiência é garantida basicamente graças à formação de governos de coalizão, aos poderes legislativos e de agenda concedidos ao Executivo, às características do sistema eleitoral e ao padrão de relacionamento Estado / Sociedade, evidenciado na relação tutor / tutelado.

Não obstante, alguns avanços têm sido apontados, levando-nos a acreditar que a accountability no Brasil, pouco a pouco parece está se fortalecendo. Dentre as principais ocorrências citadas como favorecedoras da accountability consideramos que a aprovação da Lei de Responsabilidade Fiscal merece destaque e relevância, visto que esta contempla importantes aspectos destacados pelos autores anteriormente citados, quais sejam:

Reforça as dimensões estabelecidas por O’Donnell (1998): a horizontal, quando estabelece no seu artigo 59 que a fiscalização das normas contidas na referida Lei será exercida pelo Poder Legislativo, diretamente ou com o auxílio dos Tribunais de Contas, pelo sistema de controle interno de cada Poder e pelo Ministério Público, e a vertical, quando no seu artigo 48 incentiva à participação popular e realização de audiências públicas durante os processos de elaboração e discussão dos planos, lei de diretrizes orçamentárias e da lei orçamentária anual e determinando que tais instrumentos serão objetos de ampla divulgação, inclusive em meios eletrônicos de acesso público;

Em consonância ao exposto por Stark \& Bruszt (1998) limita a autoridade do Poder Executivo, visto que procedimentaliza a conexão e a articulação entre o Plano Plurianual, a Lei de Diretrizes Orçamentárias e a Lei Orçamentária Anual, além de determinar percentuais máximos de endividamento e despesa de pessoal, entre outros;

Alinha-se a concepção de Schedler (1999), uma vez que as questões relacionadas a answerability e ao enforcement encontram- se presente de forma contundente no seu texto, tais como a publicação de relatórios e realização de audiências públicas - respectivamente informação e justificação para a primeira situação - e o estabelecimento de penalidades ao descumprimento das regras estabelecidas - punição, no caso para a segunda questão. 
Do exposto, considerando que a nossa análise está baseada apenas no referencial teórico até agora construído,concluímos que, pelo menos no campo formal, a Lei de Responsabilidade Fiscal contribui para que o processo de accountability avance no nosso país.

Não obstante, visto que para uma verdadeira accountability o exercício e o reconhecimento da cidadania devem estar presente no padrão de relacionamento Estado / Sociedade, fato ainda carente de comprovações empíricas, inclusive relacionadas às influências da Lei de Responsabilidade Fiscal no comportamento dos políticos e dos demais cidadãos, já que os dados empíricos, conforme informamos no início deste trabalho, ainda estão em fase de coleta, concluímos nosso paper reconhecendo, além da importância aprovação da referida Lei, que muitos outros passos ainda são necessários para uma melhor aproximação da accountability no Brasil. Afinal, como leciona Madison (citado por PRZEWORSKI, 1998:40):

"O objetivo de toda constituição política é, ou deveria ser, em primeiro lugar, guindar ao posto de governante os homens de maior sabedoria para identificar - e maior virtude para buscar - o bem público; o passo seguinte seria tomar todas as precauções para que os governantes se mantenham virtuosos, enquanto merecem a confiança do povo".

\section{Bibliografia}

ABRANCHES, Sergio. Presidencialismo de coalizão: O dilema institucional brasileiro. Dados, vol.3, nº 1. IUPERJ. Rio de Janeiro. 1988.

AMORIM NETO, Octávio \& TAFNER, Paulo. Governos de coalizão e mecanismos de alarme de incêndio no controle legislativo das medidas provisórias. Dados, vol.45, $\mathrm{n}^{\circ} 1$. IUPERJ. Rio de Janeiro. 2002.

ANASTASIA, Fátima \& MELO, Carlos Ranulfo F. Accountability, representação e estabilidade política no Brasil. . Em O Estado numa era de reformas: Os anos FHC (Parte 1). Coleção Gestão Pública, volume 7. Brasília, 2002.

BATISTA, Paulo Nogueira. O Consenso de Washington: a visão neoliberal dos problemas latinos-americanos. Em Em defesa do interesse nacional: Desinformação e alienação do patrimônio público. Rio de Janeiro. Paz e Terra. 1995 
CAMPOS, Anna Maria. Accountability: quando poderemos traduzi-la para o português? Revista de Administração Pública, volume 24, 1990.

DIAS FILHO, José Maria. Gestão tributária na era da responsabilidade fiscal: proposta para otimizar a curva da receita utilizando conceitos de semiótica e regressão logística. Tese de doutorado apresentada a FEA / USP. 2003

DURAND, Maria Rita Loureiro e ABRÚCIO, Fernando Luiz. As reformas fiscais no Brasil recente: Gradualismo, negociação e accountability. Em Balanço da Reforma do Estado no Brasil. Coleção Gestão Pública. Brasília, 2002.

FEDOZZI, Luciano. Orçamento participativo: reflexões sobre a experiência de Porto Alegre. Porto Alegre. Tomo Editorial. 1997.

FIGUEIREDO, Argelina Cheibub. Instituições e política no controle do executivo. Dados, volume 44, $\mathrm{n}^{\circ}$ 4. Rio de Janeiro. 2001.

KHAIR, Amir Antonio. Lei de Responsabilidade Fiscal - Guia de orientação para as Prefeituras. Brasília, 2001.

LEVY, Evelyn. Controle social e controle de resultados: um balanço dos argumentos e da experiência recente. Em O público não-estatal na reforma do Estado. FGV. Rio de Janeiro, 1999.

LINO, Pedro. Comentários à Lei de Responsabilidade Fiscal. Atlas. São Paulo, 2001.

LOUREIRO, Maria Rita \& ABRÚCIO, Fernando Luiz. Incrementalismo, negociação e accountability: Análise das reformas fiscais no Brasil. Em O Estado numa era de reformas: Os anos FHC (Parte 2). Coleção Gestão Pública, volume 7. Brasília, 2002.

NICOLAU, Jairo. Como controlar o representante? Considerações sobre as eleições para a Câmara de Deputados no Brasil. DADOS- Revista de Ciências Sociais, Rio de Janeiro, vol. $45, \mathrm{n}^{\circ} 2,2002$, pp. 219 a 236.

O’DONNELL Guillermo. Democracia delegativa? Em Novos Estudos / CEBRAP, n $^{\circ} 31$, pp.25-40. Outubro, 1991.

O’DONNELL Guillermo. Accountability horizontal e novas poliarquias. Lua Nova. $\mathrm{N}^{\circ} 44$. 1998.

PRZEWORSKI, Adam. Sobre o desenho do Estado: uma perspectiva agent X principal. Em Reforma do Estado e Administração Pública gerencial. Luiz Carlos Bresser Pereira \& Peter Spink (orgs). FGV. Rio de Janeiro. 1998.

SCHEDLER, Andreas. Conceptualizing accountability. In The self-restraing state. Power and accountability in new democracies. Andreas Schedler, Larry Diamond, Marc F. Plattner (eds). Boulder and London, Lynne Rienner Publishers, 1999. 
SCHMITTER, Philippe C. The limits of horizontal accountability. In The self-restraing state. Power and accountability in new democracies. Andreas Schedler, Larry Diamond, Marc F. Plattner (eds). Boulder and London, Lynne Rienner Publishers, 1999.

SHUGART, Mattew, MORENO, Erica \& CRISP, Brian. The accountability deficit in Latin America. Texto apresentado no seminário Instituions, Accountability and Democratic Governance in Latin America. Notre Dame,8 e 9 de maio, 2000.

STARK, David \& BRUSZT, Laszlo. Enabling constraints: Fontes institucionais de coerência nas políticas públicas no pós-socialismo. Revista Brasileira de Ciências Sociais, vol. 13, n 36. São Paulo. 1998

TROSA, Sylvie. Gestão pública por resultados: Quando o Estado se compromete. Brasília. ENAP. 2000.

VIGNOLI, Francisco Humberto (coordenador), MORAES, Adelaide M. Bezerra et alli. A Lei de Responsabilidade Fiscal comentada para municípios. São Paulo. FGV / EAESP. 2002

Artigo recebido em: 14/11/2204. Aprovado em 10/02/2005. 